Received: 19 June 2018

Accepted: 11 March 2019

Published online: 24 June 2019
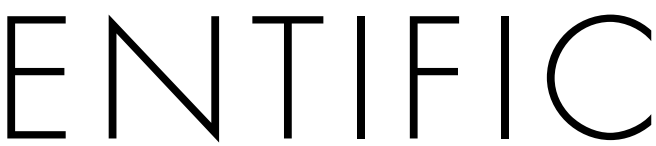

REP
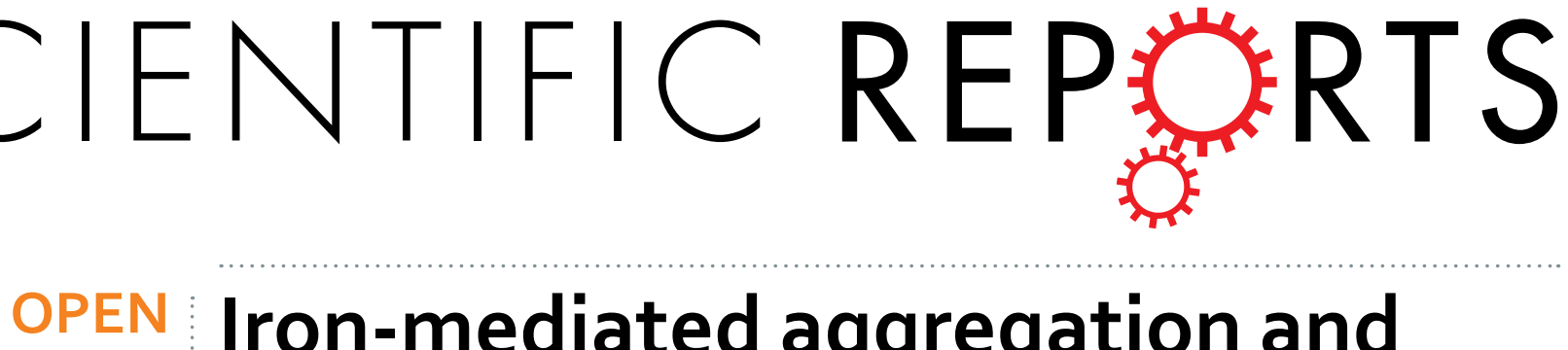

\title{
Iron-mediated aggregation and toxicity in a novel neuronal cell culture model with inducible alpha- synuclein expression
}

Martin Bartels $\mathbf{s}^{1,2}$, Daniel Weckbecker ${ }^{3}$, Peer-Hendrik Kuhn ${ }^{4}$, Sergey Ryazanov ${ }^{5,6}$, Andrei Leonov ${ }^{3,5,6}$, Christian Griesinger $\mathbb{C}^{5,6}$, Stefan F. Lichtenthaler ${ }^{7,8}$, Kai Bötzel ${ }^{2}$ \& Armin Giese ${ }^{1}$

Parkinson's disease (PD) represents an increasing problem in society. The oligomerization of alphasynuclein ( $\alpha$ Syn) is a suggested key event in its pathogenesis, yet the pathological modes of action remain to be fully elucidated. To identify potential disease-modifying therapeutics and to study $\alpha$ Synmediated toxic mechanisms, we established cell lines with inducible overexpression of different $\alpha$ Syn constructs: $\alpha$ Syn, $\alpha$ Syn coupled to the fluorescence protein Venus ( $\alpha$ Syn-Venus), and $\alpha$ Syn coupled to the N-terminal or C-terminal part of Venus (V1S and SV2, respectively) for a bimolecular fluorescence complementation assay (BiFC). Inducibility was achieved by applying modified GAL4-UAS or Cre-loxP systems and addition of tebufenozide or 4-OH-tamoxifen, respectively. Expression constructs were stably integrated into the host genome of $\mathrm{H} 4$ neuroglioma cells by lentiviral transduction. We here demonstrate a detailed investigation of the expression characteristics of inducible $\mathrm{H} 4$ cells showing low background expression and high inducibility. We observed increased protein load and aggregation of $\alpha$ Syn upon incubation with DMSO and $\mathrm{FeCl}_{3}$ along with an increase in cytotoxicity. In summary, we present a system for the creation of inducibly $\alpha$ Syn-overexpressing cell lines holding high potential for the screening for modulators of $\alpha$ Syn aggregation and $\alpha$ Syn-mediated toxicity.

Parkinson's disease (PD) represents an increasing problem in society. The loss of dopaminergic neurons in the substantia nigra (SN) and Lewy bodies or Lewy neurites in some of the remaining neurons - with $\alpha$ Syn occurring as highly ordered amyloid-type fibril as principal component - represent the histopathological hallmarks of $\mathrm{PD}^{1-3}$, yet cell loss and presence of Lewy bodies are not correlated ${ }^{4}$.

To date, several lines of evidence point towards small $\alpha$ Syn oligomers as driver of toxicity, and the small molecule modulator of $\alpha$ Syn oligomerization 3-(1,3-Benzodioxol-5-yl)-5-(3-bromophenyl)-1H-pyrazole shows beneficial effects on pathology in in vivo models of synucleinopathies ${ }^{5}$, yet - to date - the distinct toxic $\alpha$ Syn species and the pathological mechanisms are not completely understood ${ }^{6}$. It has also been suggested and discussed critically that $\alpha$ Syn may exist mainly as physiological tetramer ${ }^{7,8}$ and that the disruption of tetrameric $\alpha$ Syn to unfolded monomers represents the starting point for pathological $\alpha$ Syn aggregation ${ }^{9}$. Interestingly, the overexpression of $\alpha$ Syn appears to be sufficient to induce pathological effects, since duplication or triplication of the SNCA gene cause parkinsonian symptoms with the age of onset and severity of symptoms correlating with the gene copy number ${ }^{10-12}$. Additionally, modulating SNCA transcription by targeting the $\beta 2$-adrenoreceptor $(\beta 2 \mathrm{AR})$ using salbutamol is associated with reduced risk of developing $\mathrm{PD}^{13}$. In several epidemiological studies

${ }^{1}$ Center for Neuropathology and Prion Research, Ludwig-Maximilians-University, Munich, Germany. ${ }^{2}$ Department of Neurology, Klinikum der Universität München, Munich, Germany. ${ }^{3}$ MODAG GmbH, Wendelsheim, Germany. ${ }^{4}$ Institute of Pathology, TUM School of Medicine, Technical University of Munich, Munich, Germany. ${ }^{5}$ Center for Nanoscale Microscopy and Molecular Physiology of the Brain, Georg-August-University Göttingen, 37073, Göttingen, Germany. ${ }^{6}$ Department of NMR-based Structural Biology, Max Planck Institute for Biophysical Chemistry, 37077, Göttingen, Germany. ${ }^{7}$ German Center for Neurodegenerative Diseases (DZNE), and Munich Cluster for Systems Neurology (SyNergy), Munich, Germany. ${ }^{8}$ Neuroproteomics, School of Medicine, Klinikum rechts der Isar, and Institute for Advanced Science, Technical University of Munich, 81675, Munich, Germany. Correspondence and requests for materials should be addressed to A.G. (email: armin.giese@med.uni-muenchen.de) 


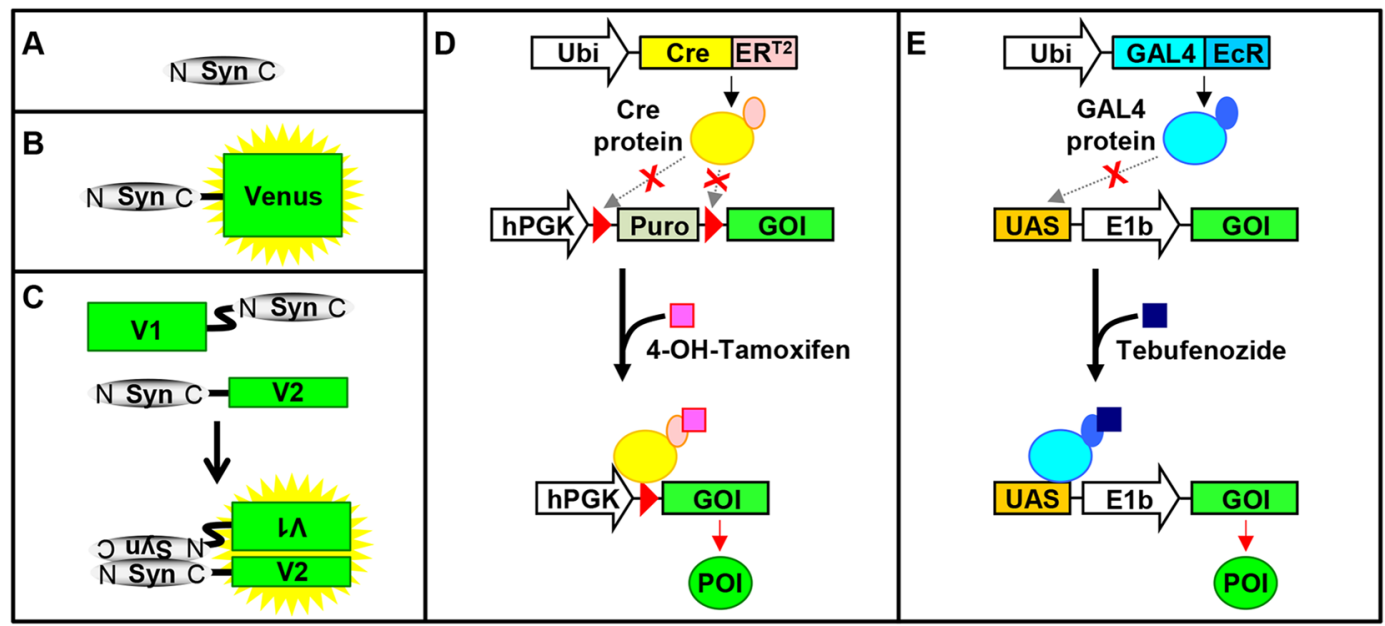

Figure 1. Induction of transgene expression in $\mathrm{H} 4$ cells. Overview of $\alpha$ Syn constructs and induction of their overexpression. (A) $\alpha$ Syn-140 (S). (B) $\alpha$ Syn-140 coupled to the fluorescence protein Venus (SV). (C) $\alpha$ Syn-140 coupled to the N-terminal (V1) or C-terminal (V2) part of Venus. Aggregation of $\alpha$ Syn results in fluorescence due to complementation of the Venus fragments. (D) Overexpression in the Cre_ER ${ }^{\mathrm{T} 2}$-loxP system $\left(\mathrm{CE}^{\mathrm{T} 2}\right)$ is induced by 4-OH-tamoxifen. (E) Overexpression in the GAL4_EcR-UAS system (GE) is induced by tebufenozide.

environmental risk factors for the development of PD have been shown to influence $\alpha$ Syn aggregation ${ }^{14}$, including the exposure to heavy metals and iron ${ }^{15}$.

So far, formation, modulation, and toxicity of $\alpha$ Syn oligomers have mainly been studied in cell models in which the overexpression of $\alpha$ Syn is induced by transient transfection ${ }^{16}$ or viral transduction ${ }^{17}$ or in cell models with stable insertion and constitutive overexpression ${ }^{18,19}$. Both strategies hold several drawbacks: (a) when using transient transfection or viral transduction, the fraction of transgene expressing cells and the strength of overexpression are subject to great inter-experimental variation. Moreover, individual experiments are rather time-consuming and expensive. Additionally, the initiation of expression cannot be defined accurately, and for several cell lines transient transfection is very inefficient. (b) Constitutive overexpression of $\alpha$ Syn on the other hand enables the investigation of $\alpha$ Syn oligomers only in steady state but not the investigation of de novo oligomer formation. This hinders the identification of compounds which prevent $\alpha$ Syn aggregation but are not capable of degrading or dissociating preformed $\alpha$ Syn aggregates leading to false-negative results in drug screening. Moreover, the constitutive overexpression of $\alpha$ Syn and the resulting $\alpha$ Syn-mediated toxicity may result in selection for cells that are resistant to $\alpha$ Syn-mediated toxicity. This might interfere with the investigation of potential toxic effects.

For these reasons, we here present a system for the fast and easy creation of cell lines with inducible overexpression of different proteins, namely $\alpha$ Syn-140 (S) (Fig. 1A) which is the most abundant splice-variant of $\alpha$ Syn in humans, the YFP variant Venus (V) ${ }^{20}, \alpha$ Syn-140 coupled to Venus (SV) (Fig. 1B), the N-terminal part of Venus coupled to $\alpha$ Syn-140 (V1S), and $\alpha$ Syn-140 coupled to the C-terminal part of Venus (SV2), where the co-expression of V1S and SV2 can be used for a bimolecular fluorescence complementation assay (BiFC) (Fig. 1C) ${ }^{19,21}$.

Overexpression relied on the Cre_ER ${ }^{\mathrm{T} 2}-\operatorname{loxP}\left(\mathrm{CE}^{\mathrm{T} 2}\right)$ system $^{22,23}$ (Fig. 1D) or the GAL4_EcR-UAS (GE) ${ }^{24}$ system (Fig. 1E). Both systems for inducible expression were successfully inserted into $\mathrm{H} 4$ cells mediated by lentiviral transduction ${ }^{25}$. Since the H4 cell lines relying on the GE system (H4_GE cells) showed higher transgene induction than the $\mathrm{H} 4$ cell lines relying on the $\mathrm{CE}^{\mathrm{T} 2}$ system ( $\mathrm{H} 4{ }_{-} \mathrm{CE}^{\mathrm{T} 2}$ cells), the expression characteristics of the tebufenozide-dependent H4_GE cells were analysed in detail. Using this cell model we further found that incubation with DMSO and ferric iron led to an increase in fluorescence intensity in the BiFC assay indicating $\alpha$ Syn oligomer formation which was confirmed by sucrose gradient centrifugation. Increased aggregation was accompanied by an increase in cytotoxicity as demonstrated by quantification of condensed nuclei in both H4_GE cells expressing V1S + SV2 and untagged $\alpha$ Syn, further validating the value of our model for studying risk factors of PD development, analysing clearance mechanisms, or screening for therapeutic compounds.

\section{Results}

Transgene expression after lentiviral transduction. After production and purification of the required lentiviruses to prepare stable cell lines we established an optimized transduction protocol to obtain as many lentivirally transduced H4 cells as possible (Supplementary Fig. 1). Following protocol D, we obtained 98\% of Venus-positive cells and the fraction of positive cells remained stable for at least 18 days after transduction. 23 days after transduction we observed a decrease in the fraction of positive cells (95\%) which was not significant $(\mathrm{p}=0.36)$ (Supplementary Fig. 2).

As a consequence, stable cell lines were created following protocol $\mathrm{D}$. This resulted in the following cell lines with inducible expression based on the GE system: H4_GE-S (inducible overexpression of $\alpha$ Syn), 
$\mathrm{H} 4$

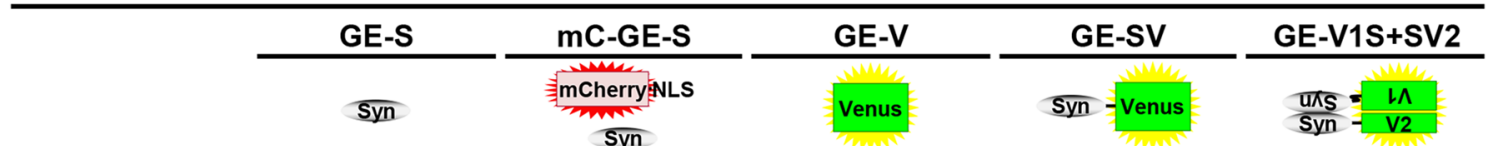

A

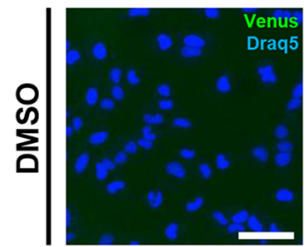

B

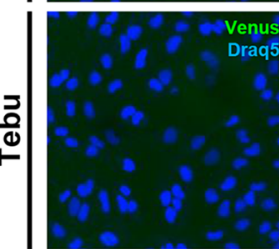

C

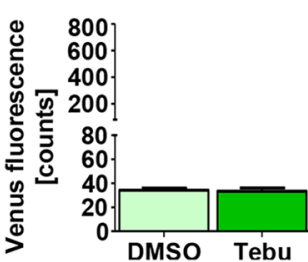

D

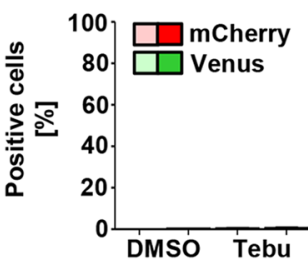

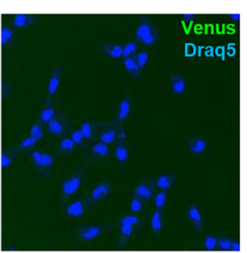
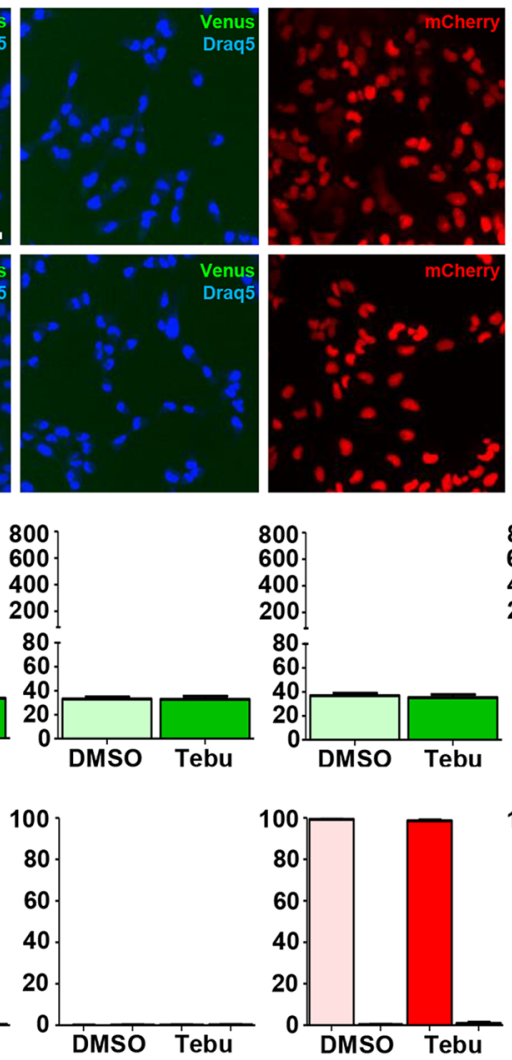
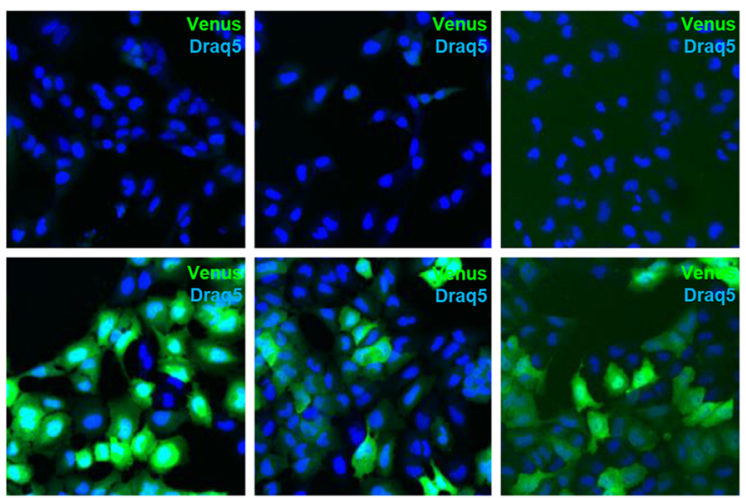

Figure 2. Induction of transgene expression in H4_GE cells. The generated H4_GE cell lines were incubated with $0.1 \%$ DMSO or $10 \mu \mathrm{M}$ tebufenozide for $48 \mathrm{~h}$ and imaged using the Opera ${ }^{\circledR}$ system. Quantification was performed using the Acapella ${ }^{\circledR}$ software. Nuclei were stained with Draq5. (A) Representative fluorescence images of cells incubated with $0.1 \%$ DMSO. Scale bar is $100 \mu \mathrm{m}$ and valid for all panels in A and B. (B) Representative fluorescence images of cells incubated with $10 \mu \mathrm{M}$ tebufenozide. (C) Quantification of the mean cellular Venus fluorescence intensity of $\mathrm{H} 4$ cells. (D) Quantification of the fraction of Venus or mCherrypositive $\mathrm{H} 4$ cells. Bars in $\mathrm{C}$ and D show mean of 3 independent experiments; error bars show SEM.

H4_mC_GE-S (constitutive expression of mCherry coupled to a nuclear localization sequence (NLS) resulting in red fluorescence in the nucleus of positively transduced cells and inducible overexpression of $\alpha$ Syn), H4_GE-V (inducible overexpression of Venus), H4_GE-SV (inducible overexpression of $\alpha$ Syn coupled to Venus), and H4_ GE-V1S + SV2 (inducible overexpression of V1S and SV2).

The following cell lines with inducible expression based on the $\mathrm{CE}^{\mathrm{T} 2}$ system were created: $\mathrm{H} 4 \mathrm{CE}^{\mathrm{T} 2}$-S (inducible overexpression of $\alpha \mathrm{Syn}$ ), $\mathrm{H} 4 \mathrm{CE}^{\mathrm{T} 2}-\mathrm{V}$ (inducible overexpression of Venus), H4_CE ${ }^{\mathrm{T} 2}-\mathrm{SV}$ (inducible overexpression of $\alpha$ Syn coupled to Venus), and H4_CE ${ }^{\mathrm{T} 2}-\mathrm{V} 1 \mathrm{~S}+\mathrm{SV} 2$ (inducible overexpression of V1S and SV2) (see Fig. 1).

Superior induction of transgene expression in H4_GE cells compared to H4_CE ${ }^{\mathrm{T} 2}$ cells. In order to test the generated H4_GE cell lines, we incubated them with $10 \mu \mathrm{M}$ tebufenozide or $0.1 \%$ DMSO as control for $48 \mathrm{~h}$ and analysed the cells using the Opera ${ }^{\circledR}$ reader. To determine the factorial increase in transgene expression upon incubation with tebufenozide, the background signal from $\mathrm{H} 4$ cells was subtracted from the signal of the corresponding inducible H4_GE cells after treatment with tebufenozide or DMSO.

As expected, we observed no green fluorescence in H4 cells, H4_GE-S cells, or H4_mC_GE-S cells independent of treatment with DMSO (Fig. 2A,C) or tebufenozide (Fig. 2B,C) and the fraction of Venus-positive cells was below 1\%. Approximately $99 \%$ of H4_mC_GE-S cells were mCherry-positive independent of tebufenozide or DMSO treatment, while the fraction of mCherry-positive cells was $0 \%$ in all other cell lines as expected. Thus, 99\% of H4_mC_GE-S cells were transduced successfully with the mCherry-NLS-UAS- $\alpha$ Syn receiver virus (V120) (Fig. 2D).

Following incubation with tebufenozide, fluorescence intensity increased considerably from 33 to 616 counts in H4_GE-V cells, from 29 to 198 counts in H4_GE-SV cells and from approximately 2.6 to 15.1 counts in H4 GE-V1S + SV2 cells, suggesting an increase in transgene expression following tebufenozide treatment by the 


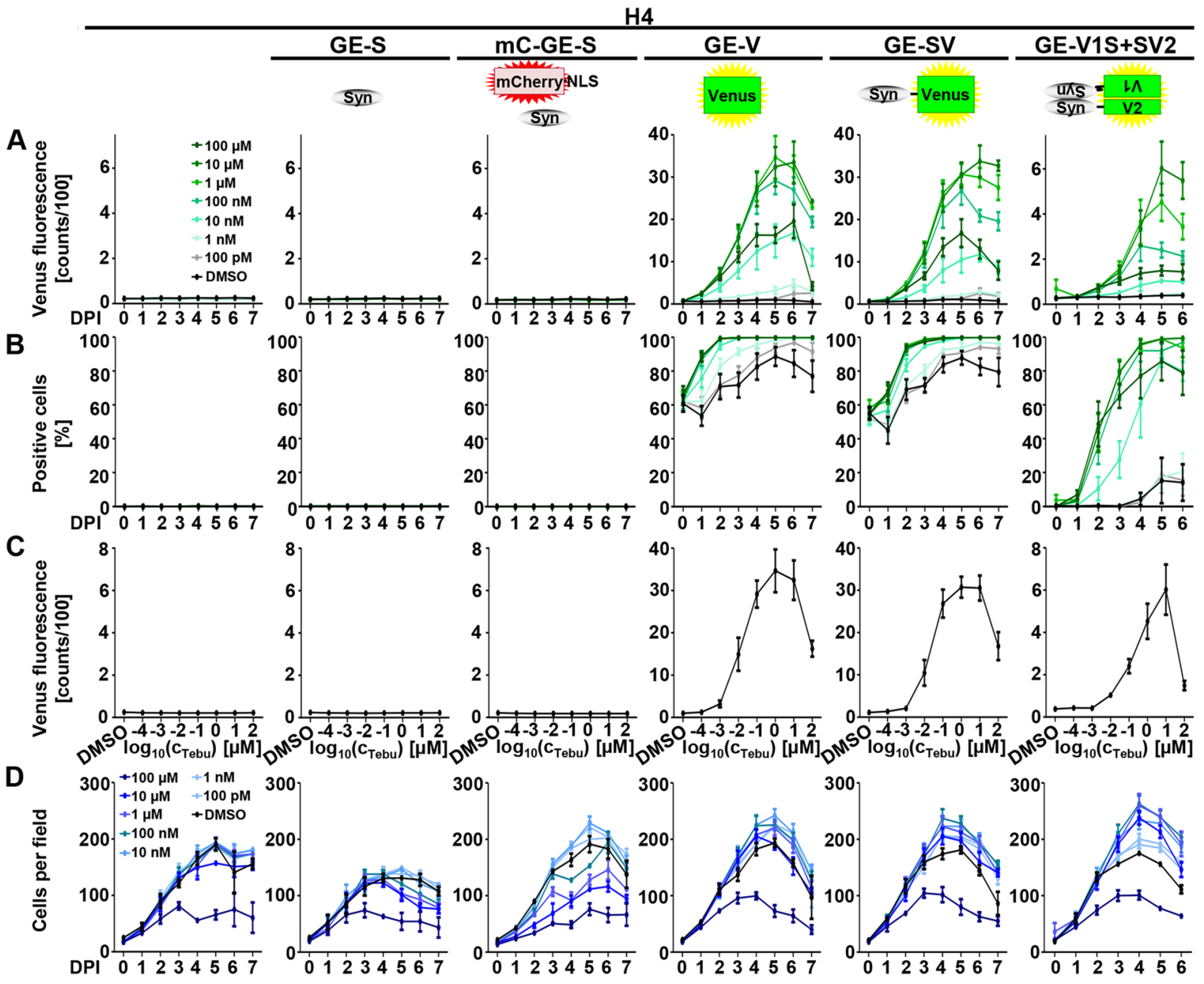

Figure 3. Expression characteristics of H4_GE cells - cellular fluorescence. H4 cell lines were incubated for up to 8 days with DMSO or with different tebufenozide concentrations ranging from $100 \mathrm{pM}$ to $100 \mu \mathrm{M}$ and imaged using the Opera ${ }^{\circledR}$ system. Quantification was performed using the Acapella ${ }^{\circledR}$ software. (A) Quantification of the mean cellular Venus fluorescence intensity of $\mathrm{H} 4$ cells upon incubation with DMSO or different concentrations of tebufenozide (color-coded). (B) Quantification of the fraction of Venus-positive $\mathrm{H} 4$ cells. (C) Quantification of the mean cellular Venus fluorescence intensity of $\mathrm{H} 4$ cells in dependence of the tebufenozide concentration using the dataset from A) at DPI 5. (D) Quantification of the number of cells per image field. Data points show mean of 3-6 independent experiments; error bars show SEM.

factor 18.7, 6.8, and 5.8, respectively (Fig. 2B,C). All cells - including Venus-negative cells - were included in the evaluation of the mean cellular Venus fluorescence of the H4_GE-V1S + SV2 cells.

For H4_GE-V and H4_GE-SV cells we observed increased background fluorescence upon treatment with DMSO compared to untreated $\mathrm{H} 4$ cells, whereas background fluorescence was in the range of unmodified $\mathrm{H} 4$ cells for DMSO-treated H4_GE-V1S + SV2 cells (Fig. 2A,C).

$\mathrm{H} 4 \mathrm{CE}^{\mathrm{T} 2}$ cell lines were incubated with $10 \mu \mathrm{M} 4$-OH-tamoxifen (since this yielded the highest fluorescence intensity without obvious adverse effects on cell shape and cell survival (Supplementary Fig. 2)) or DMSO as control for $48 \mathrm{~h}$ and analysed using the Opera ${ }^{\circledR}$ reader. Since we obtained a stronger increase in transgene expression upon treatment with tebufenozide in the H4_GE cells compared to 4-OH-tamoxifen treatment in the H4_CE ${ }^{\mathrm{T} 2}$ cells (18.6-fold vs. 2.9-fold for Venus, and 6.8-fold vs. 2.4-fold for Syn-Venus, Supplementary Fig. 3), we continued with the GE-based system for the characterization of expression kinetics.

Expression characteristics of H4_GE Cells - cellular fluorescence. In order to characterize the created H4_GE cell lines regarding their transgene expression over time and depending on tebufenozide concentration, all cell lines were incubated for up to 8 days post induction (DPI) with different tebufenozide concentrations ranging from $100 \mathrm{pM}$ to $100 \mu \mathrm{M}$ or DMSO as control, respectively.

No increase in mean cellular Venus fluorescence was observed in H4, H4_GE-S, or H4_mC_GE-S cells (Fig. 3A). In line with this, the fraction of positive cells remained $0 \%$ for all time points and tebufenozide concentrations in H4, H4_GE-S, or H4_mC_GE-S cells (Fig. 3B). Accordingly, no influence of tebufenozide 
concentration on fluorescence intensity could be observed in these cell lines (color-coded in Fig. 3A,B, and visualized for day 5 in $\mathrm{C}$ ).

On the contrary, the fluorescence signal increased in a time- and tebufenozide concentration-dependent manner from day 0 on in H4_GE-V, H4_GE-SV, and H4_GE-V1S + SV2 cells (Fig. 3A).

In H4_GE-V cells, maximum fluorescence was obtained upon incubation with $1 \mu$ M tebufenozide on DPI 5 (Fig. 3A,C) with an increase from approximately 37.9 counts (for DMSO-treated cells on DPI 0 ) to 3,439.0 counts (all values are indicated after subtraction of background signal), equivalent to a 90.8 -fold increase in fluorescence intensity. The fraction of positive cells increased from approximately $63 \%$ on DPI 0 (due to background fluorescence) to $100 \%$ on DPI 3 to 7 for cells treated with $1 \mu \mathrm{M}$ or $10 \mu \mathrm{M}$ tebufenozide, while a maximum of about $89 \%$ of DMSO-treated cells were considered Venus-positive on DPI 5.

For H4_GE-SV cells, maximum fluorescence was obtained upon incubation with $10 \mu \mathrm{M}$ tebufenozide on DPI 6 (Fig. 3A) with an increase from approximately 34.6 counts (for DMSO-treated cells at day 0) to 3,350.6 counts, equivalent to a 96.9 -fold increase in fluorescence intensity. The fraction of positive cells increased from approximately $55 \%$ on DPI 0 (due to background fluorescence) to $100 \%$ on DPI 4 to 7 for cells treated with $10 \mu \mathrm{M}$ tebufenozide, while a maximum of approximately $88 \%$ of DMSO-treated cells was Venus-positive on DPI 5 (Fig. 3B).

In H4_GE-V1S + SV2 cells fluorescence intensity increased more slowly than in H4_GE-V and H4_GE-SV cells and reached its maximum on DPI 6 upon incubation with $10 \mu \mathrm{M}$ tebufenozide (Fig. 3A) with an increase from approximately 0.4 counts (for DMSO-treated cells at DPI 0 ) to 520.5 counts, equivalent to an 1,240.7-fold increase in fluorescence intensity following tebufenozide treatment. The fraction of positive cells increased from approximately $1 \%$ on DPI 0 to $99 \%$ on DPI 5 and 6 for cells treated with $10 \mu \mathrm{M}$ tebufenozide, while a maximum of approximately $15 \%$ of DMSO-treated cells was Venus-positive on DPI 5 (Fig. 3B).

For H4_GE-V, H4_GE-SV, and H4_GE-V1S + SV2 cells, fluorescence intensity increased with increasing tebufenozide concentrations in the range of $100 \mathrm{pM}$ to $10 \mu \mathrm{M}$ and decreased when cells were incubated with $100 \mu \mathrm{M}$ tebufenozide (Fig. 3C).

For all cell lines the number of cells increased until DPI 4 or 5 . No obvious effect on cell number was observed for all tebufenozide concentrations except for treatment with $100 \mu \mathrm{M}$ tebufenozide where the number of cells was decreased in all cell lines.

Expression characteristics of H4_GE cells - protein amount depending on tebufenozide concentration. In order to further characterize the cell lines regarding their transgene expression properties in dependence of the tebufenozide concentration, the cells were incubated for 4 days with different tebufenozide concentrations ranging from $10 \mathrm{nM}$ to $10 \mu \mathrm{M}$ or with DMSO as control, respectively. After 4 days cells were harvested, lysed and subjected to Western blot analyses.

As expected, we observed no transgene expression in $\mathrm{H} 4$ cells (Fig. 4A). For all transgene-expressing cell lines we observed very little background expression upon incubation with DMSO. In all cases, protein amounts increased with increasing tebufenozide concentration up to 1 or $10 \mu \mathrm{M}$ (Fig. 4B).

Cell lines H4_GE-S, H4_mC_GE-S, H4_GE-V, and H4_GE-SV showed a maximum in transgene expression after incubation with $10 \mu \mathrm{M}$ tebufenozide, whereas maximum transgene expression in H4_GE-V1S + SV2 was observed upon incubation with $1 \mu \mathrm{M}$ tebufenozide. According to the quantification of Western blot signal intensity we obtained a maximum increase in transgene expression compared to DMSO by a factor of 16.8 in H4_GE-S, 11.5 in H4_mC_GE-S, 5.6 in H4_GE-V, 7.2 in H4_GE-SV, and 11.9 in H4_GE-V1S + SV2 for SV2 expression. Concerning the expression of V1S in H4_GE-V1S + SV2 the factorial increase in transgene expression could not be evaluated since no background signal for treatment with DMSO was detected.

Expression characteristics of H4_GE cells - kinetics of protein amount. In order to further characterize the cell lines regarding their expression kinetics according to protein levels, the cells were incubated for up to 5 days with $10 \mu \mathrm{M}$ tebufenozide since this reached the highest transgene expression in most cell lines (see Figs 3,4$)$. Cells were harvested, lysed and subjected to Western blot analyses on DPI $0,1,2,3,4$, and 5.

As expected, no transgene expression was observed in $\mathrm{H} 4$ cells (Fig. 5A). For all transgene expressing cell lines we observed very little background expression in the absence of tebufenozide (DPI 0) and an increase in protein amounts over time (Fig. 5B). According to the quantification of Western blot signal intensity we obtained a maximum increase in protein amount by a factor of 25.1 in H4_GE-S, 13.1 in H4_mC_GE-S, 43.8 in H4_GE-SV, and 5.5 in H4_GE-V. For H4_GE-V1S + SV2 the factorial increase in protein amounts could not be evaluated since no background signal was observed on DPI 0.

Increased $\alpha$ Syn aggregation and $\alpha$ Syn-Mediated cytotoxicity upon incubation with DMSO and ferric iron. DMSO and ferric iron have been shown to increase aggregation of $\alpha$ Syn in vitro ${ }^{15}$. In order to validate our model, we investigated if this effect of DMSO and ferric iron on $\alpha$ Syn aggregation could be reproduced in the H4_GE cell model. For this, H4_GE-V1S + SV2 and H4_GE-V cells were incubated with different combinations of DMSO (ranging from $0.1 \%$ to $1.0 \%$ ) and $\mathrm{FeCl}_{3}$ concentrations (ranging from $0 \mu \mathrm{M}$ to $1 \mathrm{mM}$ ) for 3 days. Transgene expression was induced with $10 \mu \mathrm{M}$ tebufenozide in H4_GE-V1S + SV2 cells and with $10 \mathrm{nM}$ tebufenozide in H4_GE-V cells for three days in order to reach comparable fluorescence intensities. After 3 days, cellular fluorescence intensity was determined using the Opera ${ }^{\circledR}$ setup.

We found an increase in fluorescence intensity with increasing DMSO and $\mathrm{FeCl}_{3}$ concentrations in $\mathrm{H}_{4}$ GE-V1S + SV2 cells (Fig. 6, A left) but not in H4_GE-V cells (Fig. 6, A right). The increase in fluorescence intensity was most prominent for incubation with $\mathrm{FeCl}_{3}$ compared to other tri-, di-, or monovalent metal ions (Fig. 6B). 
A

H4
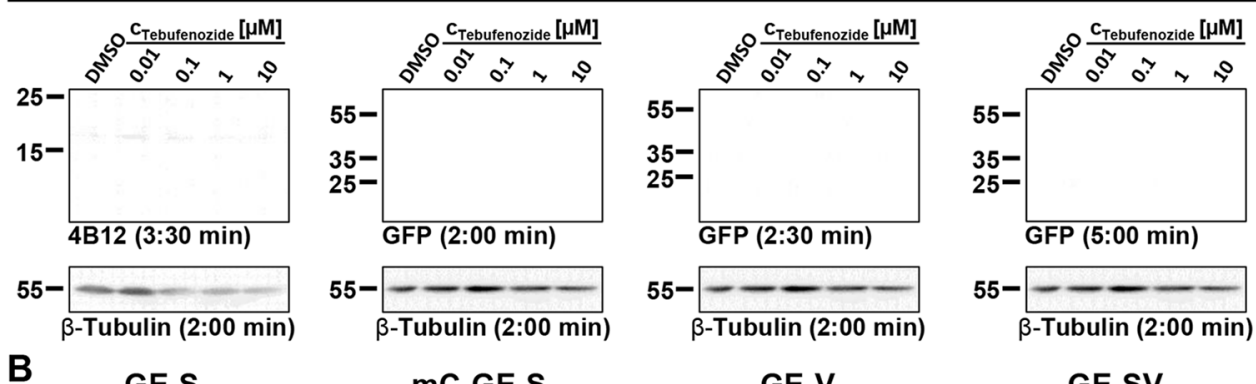

B GE-S

MC-GE-S

GE-V

GE-SV

GE-V1S+SV2

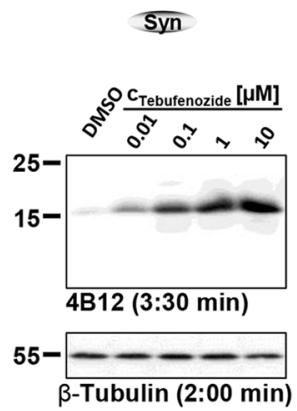

mCherry ${ }^{\prime}$ LS

Syn

Venus

Syn - Venus
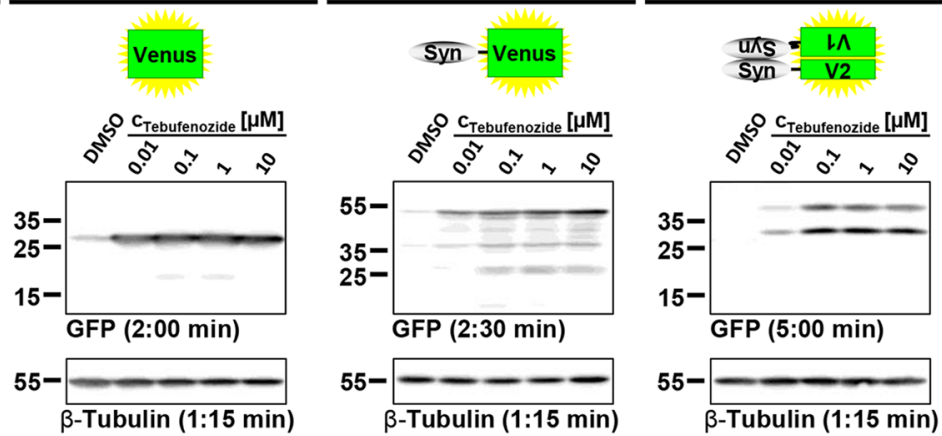

C
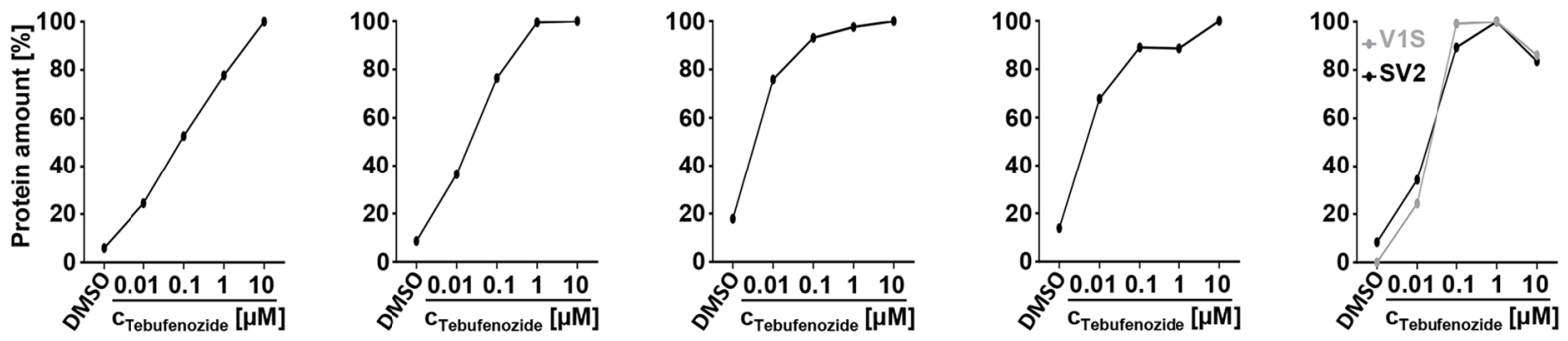

Figure 4. Expression characteristics of H4_GE cells - protein amounts depending on tebufenozide concentration. H4 cell lines were incubated for 4 days with DMSO or different tebufenozide concentrations ranging from $10 \mathrm{nM}$ to $10 \mu \mathrm{M}$. For all samples, expression of housekeeper $\beta$-tubulin was used as reference. (A) Control Western blots of $\mathrm{H} 4$ cells were treated like the Western blots of the corresponding samples and showed no expression of $\alpha$ Syn, Venus, SV, V1S, or SV2. (B) In all transgene expressing cell lines signal intensity increased with increasing tebufenozide concentration up to $1 \mu \mathrm{M}$ or $10 \mu \mathrm{M}$ for inducible transgenes. Full-length Western blots and additional exposures are shown in Supplementary Figs 5, 6, respectively. (C) Quantification of Western blot signal intensity was performed using ImageJ. Signal intensity of transgenes was normalized to maximum. Data points were derived from the blots shown in A and B.

To test if the observed increase in fluorescence intensity in the BiFC assay was due to $\alpha$ Syn aggregation, we also analysed the effect of DMSO and ferric iron on protein amount of cells overexpressing variants of $\alpha \mathrm{Syn}$ (H4 GE-S and H4_GE-V1S + SV2) compared to H4_GE-V cells overexpressing Venus. Since we observed many dead and rounded cells upon incubation with $1 \% \mathrm{DMSO}$ and iron precipitation upon incubation with $1 \mathrm{mM} \mathrm{FeCl}_{3}$, we chose the conditions $0.75 \%$ DMSO and $100 \mu \mathrm{M} \mathrm{FeCl}_{3}$ versus $0.1 \% \mathrm{DMSO}$ and $0 \mu \mathrm{M} \mathrm{FeCl}$. We observed an increase in protein amount in H4_GE-S and H4_GE-V1S + SV2 upon treatment with $0.75 \%$ DMSO and $100 \mu \mathrm{M}$ $\mathrm{FeCl}_{3}$ compared to incubation with $0.1 \%$ DMSO, while there was no effect on Venus protein amount in H4_GE-V cells (Fig. 7A). An increase in $\alpha$ Syn protein load upon its aggregation has been reported before ${ }^{26}$ and might be due to reduced degradation of aggregated $\alpha$ Syn.

We additionally analysed the aggregation state of $\alpha$ Syn in those cells using sucrose gradient centrifugation. We observed higher molecular $\alpha$ Syn species (occurring in fractions with higher sucrose concentrations) when cells were treated with $0.75 \%$ DMSO and $100 \mu \mathrm{M} \mathrm{FeCl}_{3}$ for H4_GE-S and H4_GE-V1S + SV2 cells compared to cells treated with $0.1 \%$ DMSO. In contrast, we found no difference between both treatments in H4_GE-V cells (Fig. 7B).

Moreover, we developed an evaluation script for the quantification of cell death relying on the analysis of nuclear morphology. We here observed a strong increase in the fraction of condensed nuclei in $\mathrm{H} 4$ cell lines overexpressing $\alpha$ Syn compared to Venus-overexpressing cells upon incubation with $0.75 \%$ DMSO and $100 \mu \mathrm{M} \mathrm{FeCl}_{3}$.

In line with the in vitro findings from Kostka et al. ${ }^{15}$, these findings suggest increased aggregation of $\alpha$ Syn in $\mathrm{H} 4$ _GE cells upon incubation with high concentrations of $\mathrm{DMSO}$ and $\mathrm{FeCl}_{3}$ which goes along with increased 
A

H4

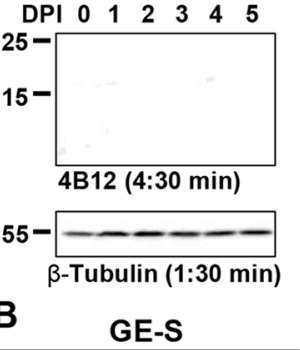

DPI $\begin{array}{llllll}0 & 1 & 2 & 3 & 4 & 5\end{array}$

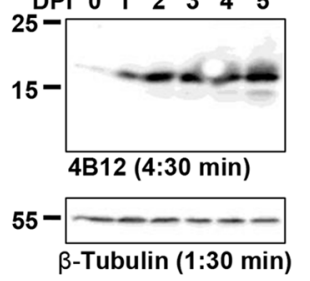

C

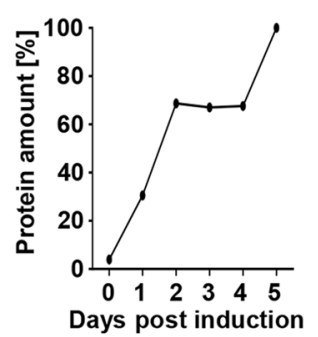

DPI $\begin{array}{llllll}0 & 1 & 2 & 3 & 4 & 5\end{array}$

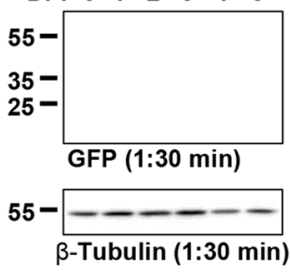

mC-GE-S

mCherry NLS

Syn
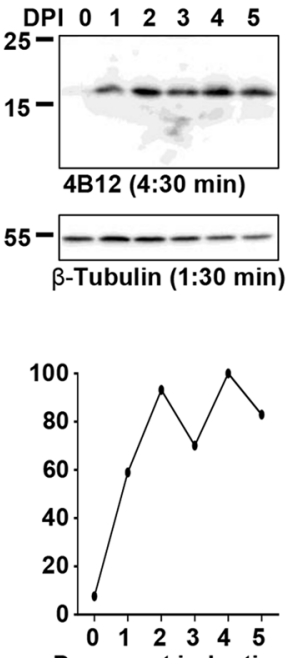

Days post induction

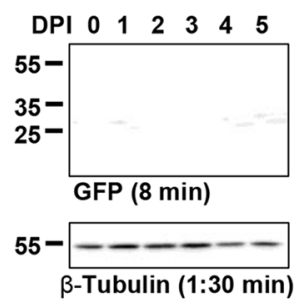

GE-V

GE-SV
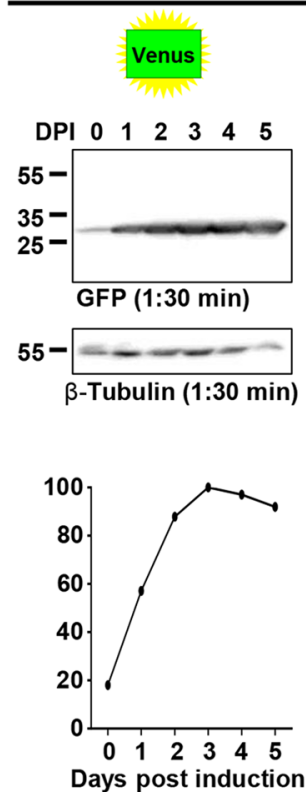
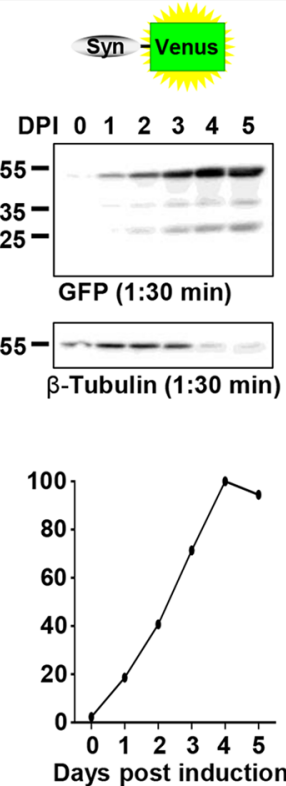

GE-V1S+SV2

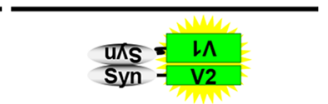

Figure 5. Expression characteristics of H4_GE cells - kinetics of protein amounts. $\mathrm{H} 4$ cell lines were incubated with $10 \mu \mathrm{M}$ tebufenozide for 0 to 5 days. For all samples, expression of housekeeper $\beta$-tubulin was used as reference. (A) Control Western blots of $\mathrm{H} 4$ cells were treated like the Western blots of the corresponding samples and showed no expression of $\alpha$ Syn, Venus, SV, V1S, or SV2. (B) In all transgene expressing cell lines signal intensity increased over time for inducible transgenes. Full-length Western blots and additional exposures are shown in Supplementary Figs 7, 8, respectively. (C) Quantification of Western blot signal intensity was performed using ImageJ. Signal intensity of transgenes was normalized to maximum. Data points were derived from the blots shown in $\mathrm{A}$ and $\mathrm{B}$.

cytotoxicity. The findings from the BiFC-assay in H4_GE-V1S + SV2 cells were confirmed in cell lines expressing untagged $\alpha$ Syn, further validating the significance of our model system.

\section{Discussion}

We here present the development of $\mathrm{H} 4$ cells that stably and inducibly overexpress different constructs, namely wt $\alpha$ Syn (S), the YFP variant Venus (V), $\alpha$ Syn coupled to Venus (SV), and constructs for a BiFC assay (V1S and SV2). Inducible H4_GE and H4_CE ${ }^{\mathrm{T} 2}$ cells were created using lentiviral transduction resulting in long-term stable gene expression (Supplementary Fig. 1). In order to minimize interexperimental variations of cellular characteristics we applied a strategy where we obtained 300 aliquots of cells with theoretically identical properties for all cell lines. Since a new aliquot is used for every single experiment, a stable transgene expression over a time-course of 23 days (Supplementary Fig. 1) appears to be sufficient.

Since we obtained higher transgene inducibility in pilot experiments for the GE over the $\mathrm{CE}^{\mathrm{T} 2}$ system we performed a detailed characterization of its expression characteristics using the Opera ${ }^{\circledR}$ system and Western blot analyses and obtained almost $100 \%$ of transgene expressing cells for all H4_GE cell lines that express fluorescence proteins (H4_mC_GE-S (Fig. 2D), H4_GE-V, H4_GE-SV, and H4_GE-V1S + SV2 (Fig. 3B)). Thus, it is likely that we also obtained a very high fraction of $\alpha$ Syn-expressing cells in the H4_GE-S cell line. We found that mean cellular fluorescence intensity showed a maximum at day 5 or 6 (Fig. 3A). This corresponds to the data obtained from the Western blot evaluation of expression kinetics (Fig. 5). Recently, the development of a comparable model for inducible expression of $\alpha$ Syn in $\mathrm{H} 4$ cells has been published ${ }^{27}$. Like for our model, Moussaud et al. observed low background expression and an increase in transgene expression over time, reaching a maximum 4 to 6 days after induction (Figs 3,5). A reliable comparison of the characteristics of both models would require the investigation of both kinds of cell lines in parallel under equal conditions and is difficult from published data alone. 


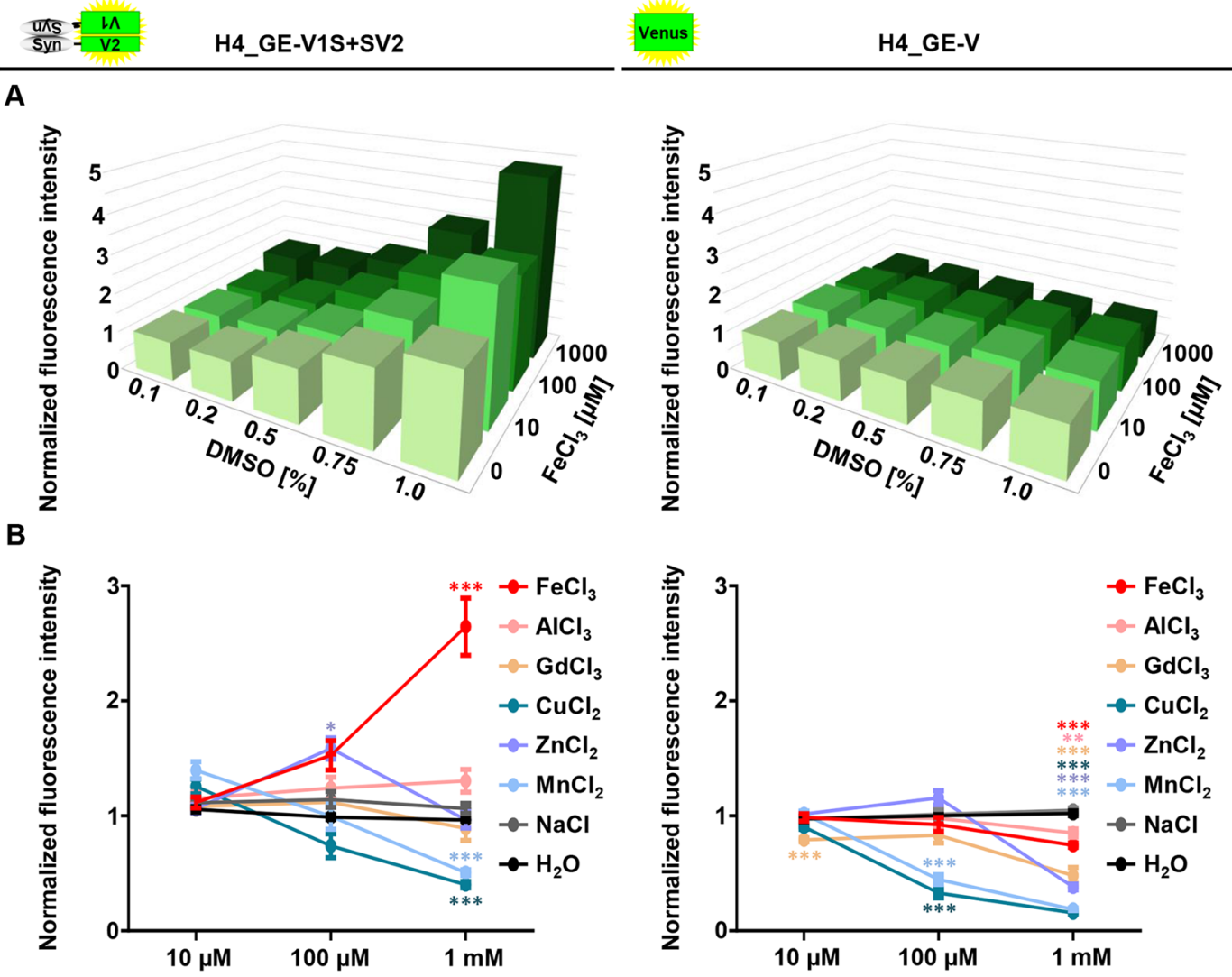

Figure 6. Increased fluorescence intensity in H4_GE-V1S + SV2 cells upon incubation with DMSO and $\mathrm{FeCl}_{3}$. H4_GE-V1S + SV2 and H4_GE-V cells were incubated with tebufenozide and different concentrations of DMSO and tri-, di-, or monovalent ions for 3 days. (A) Mean cellular Venus fluorescence intensity was increased upon incubation with higher DMSO and $\mathrm{FeCl}_{3}$ concentrations in H4_GE-V1S + SV2 cells (left), but not in H4_GE-V cells (right). Bars show mean of three independent experiments. (B) Fluorescence intensity increased upon incubation with $\mathrm{FeCl}_{3}$ compared to other trivalent $\left(\mathrm{AlCl}_{3}, \mathrm{GdCl}_{3}\right)$, divalent $\left(\mathrm{CuCl}_{2}, \mathrm{ZnCl}_{2}\right.$, $\mathrm{MnCl}_{2}$ ), or monovalent $(\mathrm{NaCl})$ ions. All cells were co-incubated with $1 \%$ DMSO. Data points show mean of 8 to 9 independent experiments; error bars show SEM. * $\mathrm{p}^{\prime}<0.05$; ** $\mathrm{p}^{\prime}<0.01$; *** $\mathrm{p}^{\prime}<0.001$ (Student's t-test, Bonferroni corrected for multi-testing).

However, since the model developed by Moussaud et al. relies on transient transfection and a Tet-Off system it is limited to cell lines which are susceptible to transient transfection and which do not apply a tetracyclin based expression system for additional mechanisms. Since our system is applied via lentiviral transduction and is independent of tetracyclin, it holds the additional benefit that it can be applied to cell lines which are not susceptible to transient transfection and use a Tet-On or Tet-Off system for inducible expression of other proteins - including primary cells and LUHMES cells ${ }^{28,29}$.

Interestingly, the fluorescence intensity and the fraction of positive cells increased more slowly in the $\mathrm{H} 4$ GE-V1S + SV2 cells compared to H4_GE-V or H4_GE-SV cells (Fig. 3), while protein amounts increased in a comparable fashion (Fig. 5). This might be due to the fact that a detectable fluorescence signal in the BiFC system requires not only expression of a fluorescence protein but also nucleation of $\alpha$ Syn aggregation. This is supported by investigation of the kinetics of protein amount in H4_GE-V1S + SV2 cells which showed a rather exponential increase in fluorescence intensity over time (Fig. 3A) whereas protein amounts of V1S and SV2 increased rather linearly (Fig. 5). Interestingly, Moussaud et al. observed $\alpha$ Syn immunoreactivity in $\mathrm{H} 4 \mathrm{BiFC}$ cells which did not display Venus fluorescence suggesting the presence of monomeric $\alpha \operatorname{Syn}^{27}$.

Furthermore, we found that fluorescence intensity increased in a tebufenozide-dependent manner upon incubation with $1 \mathrm{nM}$ to $10 \mu \mathrm{M}$ tebufenozide (Fig. 3A,C). These data are in line with our investigation of protein amounts increasing with tebufenozide concentration using Western blot analysis (Fig. 4) and with previously published data ${ }^{24}$. The decreased fluorescence intensity observed when incubating cells with $100 \mu \mathrm{M}$ tebufenozide can most likely be explained by precipitation of tebufenozide. Background expression in the absence of tebufenozide was very low or not detectable at all for all H4_GE cell lines (Figs 2A-C, 3A, 4).

$\mathrm{BiFC}$ systems have been widely used to study protein-protein interactions in general ${ }^{21,30}$ and oligomerization of $\alpha$ Syn in particular ${ }^{19,31}$, yet protein tags in general possibly interfer with protein functions. It has been shown that Venus protein tags for $\alpha$ Syn complementation assays do neither interfere with the normal cellular distribution of $\alpha$ Syn nor with the polymerization of $\alpha$ Syn, yet, $\alpha$ Syn half-life and oligomer stability appeared to be increased in fluorescence protein-based BiFC cells, probably due to an irreversibility of fragment complementation ${ }^{27,32-34}$. 


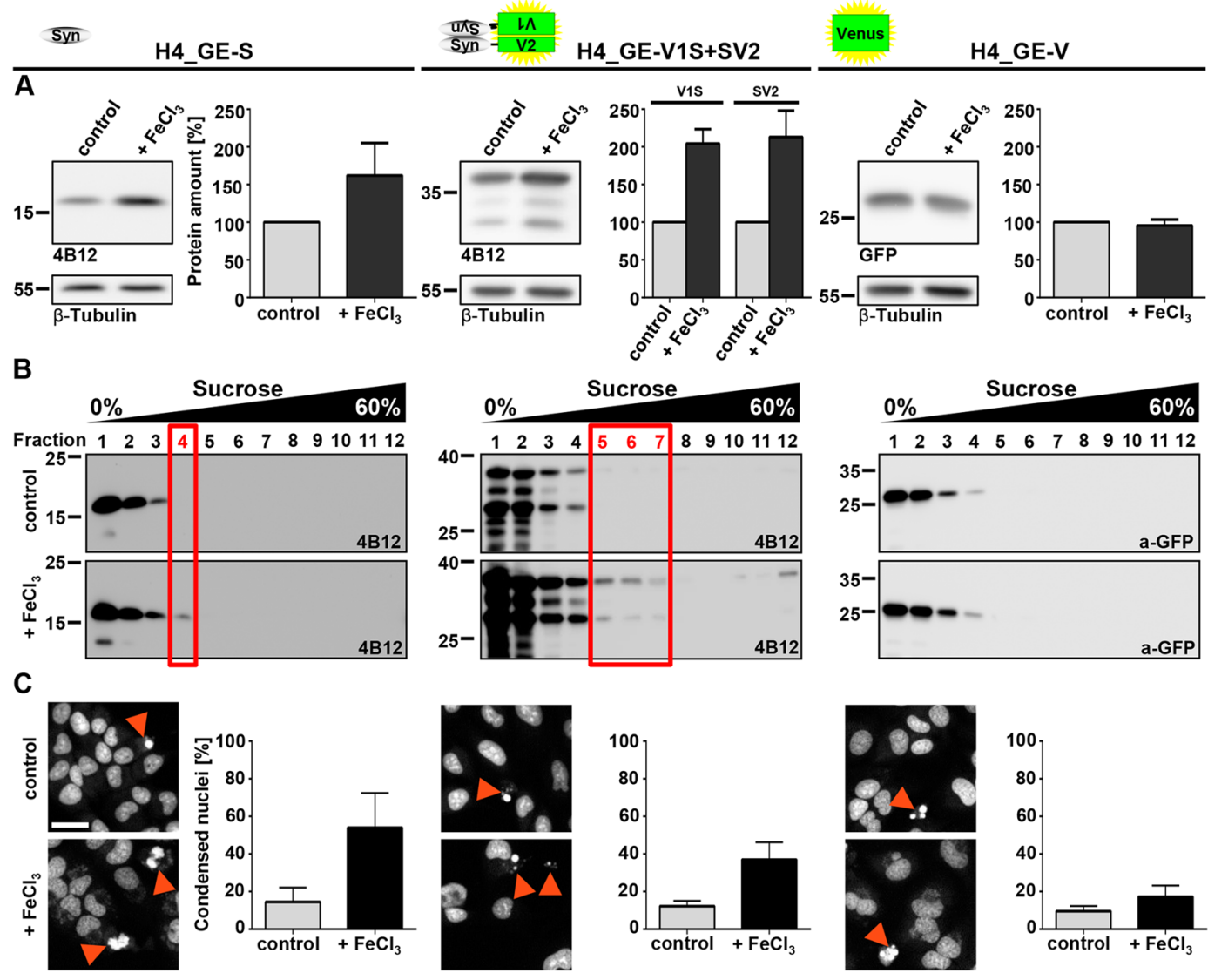

Figure 7. Increased protein amount and aggregation in $\alpha$ Syn-overexpressing H4_GE cells upon incubation with DMSO and $\mathrm{FeCl}_{3}$. H4_GE-S, H4_GE-V1S + SV2 and H4_GE-V cells were incubated with 0.75\% DMSO and $100 \mu \mathrm{M} \mathrm{FeCl}_{3}\left(+\mathrm{FeCl}_{3}\right)$ or $0.1 \%$ DMSO (control) for 3 days. (A) Protein amounts increased in cell lines overexpressing variants of $\alpha$ Syn but not in cells overexpressing Venus upon incubation with $0.75 \%$ DMSO and $100 \mu \mathrm{M} \mathrm{FeCl}_{3}$. For quantification signals were normalized to housekeeper. Signals from samples treated with $0.1 \%$ DMSO were set to $100 \%$. Bars show mean of 3 to 4 independent experiments and error bars show SEM. Full-length Western blots and additional exposures are shown in Supplementary Figs 9A, 10A, respectively. (B) Representative Western blots from cell lysates after sucrose gradient centrifugation of H4_GE-S (left), H4_GE$\mathrm{V} 1 \mathrm{~S}+\mathrm{SV} 2$ (middle) and H4_GE-V cells (right) incubated with $0.1 \% \mathrm{DMSO}$ and $0 \mu \mathrm{M} \mathrm{FeCl}_{3}$ (top) or $0.75 \%$ DMSO and $100 \mu \mathrm{M} \mathrm{FeCl}_{3}$ (bottom) demonstrating an increase in high molecular weight species in cell lines overexpressing variants of $\alpha$ Syn but not in cells overexpressing Venus following treatment with 0.75\% DMSO and $100 \mu \mathrm{M} \mathrm{FeCl}_{3}(\mathrm{n}=3)$. Full-length Western blots and additional exposures are shown in Supplementary Figs 9B, 10B, respectively. (C) The fraction of condensed nuclei (red arrowheads) was considerably increased in $\alpha$ Syn-overexpressing cells, but only slightly in Venus-overexpressing cells following incubation with $0.75 \%$ DMSO and $100 \mu \mathrm{M} \mathrm{FeCl}_{3}$ suggesting increased cytotoxicity. Scale bar is $50 \mu \mathrm{m}$ and valid for all panels. Bars show mean of 4 independent experiments, error bars show SEM.

Moreover, protein tags and protein complementation assays have been applied successfully to study $\alpha$ Syn associated aspects including investigation of molecular disease mechanisms ${ }^{35}$, cell based screening assays ${ }^{27}$, and in vivo-models ${ }^{36}$. However, to account for a possible effect of the protein tags on the function of $\alpha$ Syn we included extensive control experiments using untagged $\alpha$ Syn. Importantly, cells expressing untagged $\alpha$ Syn showed similar results regarding iron-induced aggregation of $\alpha$ Syn and $\alpha$ Syn-mediated toxicity (Fig. 7) as cells expression the $\alpha$ Syn-Venus fusion constructs. In the fusion system used in this study the Venus fragments are coupled to the $\mathrm{N}$ - and C-terminal end of $\alpha$ Syn since this led to highest fluorescence yield ${ }^{19}$, probably emphasizing the detection of oligomers with an anti-parallel assembly of $\alpha$ Syn.

It has been described before that the fluorescence-based $\alpha$ Syn PCA can be used as high-throughput primary assay to screen large libraries ${ }^{27}$ which is in line with our experiment to screen for aggregation enhancers (Fig. 6B). We additionally performed a proof-of-concept experiment using known modulators of $\alpha$ Syn aggregation ${ }^{5,15,37-41}$. As expected, we observed reduced fluorescence intensity using these compounds (Supplementary Fig. 4) further validating the relevance of our model for screening assays. All in all, our findings further support the relevance of $\mathrm{BiFC}$-based inducible $\alpha$ Syn cell models as valuable tools in drug discovery for PD.

Iron has been discussed extensively and controversially as possible risk factor for the development of PD ${ }^{14}$. Taken together, our data suggest an increase in $\alpha$ Syn aggregation in H4_GE cells upon incubation with DMSO and $\mathrm{FeCl}_{3}$ (Figs 6,7) which is well in line with previously published in vitro experiments ${ }^{15}$ and thus serves as a 
proof-of-concept of the presented cell model. Here, the occurrence of high molecular species after sucrose gradient centrifugation was more pronounced in H4_GE-V1S + SV2 cells compared to H4_GE-S cells (Fig. 7B). This may be explained by a stabilizing effect of the complementation of the Venus fragments on oligomeric $\alpha$ Syn species $^{19}$. We also observed an increase in cytotoxicity with $\alpha$ Syn aggregation, which was assessed by label-free quantification of condensed nuclei (Fig. 7C). Interestingly, this was more pronounced in those cells that overexpress untagged $\alpha$ Syn compared to the cells expressing V1S + SV2. This could be due to hampered formation of toxic oligomeric $\alpha$ Syn species as a result of the fluorescence tags or the complementation of the Venus fragments. Taken together, our data on increased aggregation and $\alpha$ Syn-mediated cytotoxicity following exposure to DMSO and $\mathrm{FeCl}_{3}$ are well in line with several findings that point towards ferric iron as an important player in the course of pathology further validating the significance of our cell model. Indeed, elevated brain iron levels with a shift in the $\mathrm{Fe}^{2+} / \mathrm{Fe}^{3+}$ ratio in favour of $\mathrm{Fe}^{3+}$ have been observed in the SN of PD patients and a neuroprotective effect of iron chelators has been described ${ }^{42}$. Furthermore, iron has been shown to promote aggregation of $\alpha$ Syn resulting in toxicity in cell culture ${ }^{43}$, and incubation with ferric iron has produced pore-forming $\alpha$ Syn oligomers in vitro ${ }^{15,44,45}$. While our investigations on iron-dependent $\alpha$ Syn aggregation reproduce earlier in vitro findings and validate the value of our cell model, the current study is limited regarding molecular mechanisms by which iron acts on $\alpha$ Syn aggregation. However, it has been described earlier that iron directly interacts with $\alpha \operatorname{Syn}^{44}$ and with iron response elements in the $5^{\prime}$ untranslated region in its $\mathrm{mRNA}^{46}$.

To date, there is no cure and no disease-modifying therapy for PD available. Therefore, a better understanding of underlying disease mechanisms is inevitable for the development of better diagnostic tools - allowing an earlier and more reliable diagnosis of PD - and for the development of disease-modifying therapies. We here present an important tool for the investigation of $\alpha$ Syn aggregation and the discovery and detailed characterization of novel drug candidates which can finally be translated to clinical application.

\section{Methods}

Plasmid cloning. Plasmids and primers are summarized in Supplementary Table 1 and Supplementary Table 2, respectively.

Constructs S, V1S, SV2, SV, and V were amplified from plasmids \#1-\#4 (kind gift from Pamela McLean). S was amplified from plasmid \#3 using primers MB8_SV_Hind3_f and MB11_Syn_Not1_r, V1S from plasmid \#1 (primers MB24_V1_HindIIIf and MB6_V1S_Not1_r), SV2 from plasmid \#2 (primers MB3_SV2_Hind3_f and MB25_V2_NotI_r), SV from plasmid \#3 (primers MB8_SV_Hind3_f and MB9_SV_PspOMI_r), V from plasmid \#3 (primers MB10_V_Hind3_f and MB9_SV_PspOMI_r).

For lentiviral expression plasmids, constructs were inserted between the HindIII and NotI site of pCR8/GW/ TOPO + pCS2-MCS and then transferred to the destination vectors 636, 597, \#44, and \#92 (Supplementary Table 1), using the Gateway ${ }^{\circledR}$ Technology ${ }^{47}$. Vector \#92 was created by amplifying mCherry-NLS from plasmid $\# 87^{48}$ (pmCherry-NLS was a gift from Martin Offterdinger (Addgene plasmid \# 39319)) using primers 42MB_ SalI-mCherry_f and 43MB_NsiI_mCherry_r and subcloning between the XhoI and NsiI sites of plasmid \#45.

To create plasmid \#71, V1S was amplified from plasmid \#1 using primers MB24_V1_HindIIIf and MB6_ V1S_Not1_r. For plasmid \#75, SV2 was amplified from plasmid \#2 (primers MB3_SV2_Hind3_f and MB25_ V2_NotI_r). Both constructs were subcloned between the HindIII and NotI sites of P12-HA-TGFa-FLAG (Supplementary Table 1$)^{49}$.

Cell maintenance. HEK293T cells (ATCC, CRL-3216) were maintained in DMEM (PAN, P04-03600) supplemented with $1 \%$ glutamine (PAN, P04-80100) and 10\% fetal bovine serum (FBS; PAN, P30-3702). H4 human neuroglioma cells (ATCC, HTB-148) were maintained in Opti-MEM (Invitrogen, 31985-070) supplemented with $10 \%$ FBS (PAN, P30-3702). Cells were grown at $37^{\circ} \mathrm{C}$ in a humidified $95 \%$ air $/ 5 \% \mathrm{CO}_{2}$ atmosphere and passaged twice weekly. All cell lines were regularly tested for mycoplasma contamination.

Virus production and purification. Packaging plasmids \#97 and \#98, and corresponding expression plasmids (see Supplementary Table 3) were transfected into HEK293T cells using Lipofectamine ${ }^{\circledR} 2000$ according to the manufacturer's instructions.

Virus-containing medium was collected after $48 \mathrm{~h}$ and $72 \mathrm{~h}$ and centrifuged (3,000 rcf, $15 \mathrm{~min}$ ). Afterwards, supernatant was filtered using a $0.45-\mu \mathrm{m}$ filter and centrifuged $\left(22,000 \mathrm{rpm}, 2 \mathrm{~h}, 4^{\circ} \mathrm{C}\right.$, SW2 2 rotor (Beckman Coulter, 342196), Sorvall Discovery 90SE ultracentrifuge). Pellets were incubated in TBS-5 buffer (50 mM Tris- $\mathrm{HCl}$ ( $\mathrm{pH} 7.8$ ), $130 \mathrm{mM} \mathrm{NaCl}, 10 \mathrm{mM} \mathrm{KCl}, 5 \mathrm{mM} \mathrm{MgCl}_{2}, 10 \% \mathrm{BSA}(\mathrm{w} / \mathrm{V})$ ), sterile filtered) overnight, then centrifuged ( $\left.800 \mathrm{rcf}, 2 \mathrm{~min}, 4^{\circ} \mathrm{C}\right)$. Supernatant was frozen in $20 \mu \mathrm{l}$ aliquots at $-80^{\circ} \mathrm{C}$.

Compound testing. $100,000 \mathrm{cells} / \mathrm{ml}$ were incubated with $0.1 \%$ DMSO as a control or $10 \mu \mathrm{M}$ 3-(1,3-Benzodioxol-5-yl)-5-(3-bromophenyl)-1H-pyrazole or anle138c (synthesized as described previously $^{5}$ ) with a final DMSO concentration of $0.1 \%$. After $24 \mathrm{~h}$, cells were washed with DPBS and fresh normal growth medium was added. Afterwards, cells were transiently transfected with plasmids \#71 and \#75 using X-tremeGENE ${ }^{\mathrm{TM}} \mathrm{HP}$ DNA Transfection Reagent according to the manufacturer's instructions $\left(3 \mu \mathrm{l} / \mu \mathrm{g}_{\text {plasmid }}\right.$; Roche Diagnostics, 06366236001). After $2 \mathrm{~h}$, cells were washed with DPBS and fresh normal growth medium containing the corresponding compound or DMSO was added for $48 \mathrm{~h}$.

Optimization of the $\mathrm{H} 4$ transduction protocol. To optimize the transduction protocol we determined the fraction of fluorescing cells for different protocols manually using the ImageJ software.

Protocol A: V99 and V41 were diluted 1:200 in $2 \mathrm{ml}$ of cell-containing medium (50,000 cells $/ \mathrm{ml})$.

Protocol B: V99 and V41 were diluted 1:50 in $2 \mathrm{ml}$ cell-containing medium $(50,000 \mathrm{cell} / \mathrm{s} / \mathrm{ml})$.

Protocol C: V99 and V41 were diluted 1:12 in $200 \mu \mathrm{l}$ cell-containing medium (100,000 cells/ml). 
Protocol D: V41 was diluted 1:3.5 in $50 \mu \mathrm{l}$ cell-containing medium. Cells were expanded and maintained as described above. After two weeks, the obtained H4_41 cells were transduced with V99.

For all protocols, cell nuclei were stained with $0.5 \mu \mathrm{g} / \mathrm{ml}$ Hoechst33342 (Invitrogen, H1399) $72 \mathrm{~h}$ after transduction.

Creation of stable inducible $\mathrm{H} 4$ cell lines. H4 cells were transduced according to protocol D (described above). For the GE system, cells were transduced with V100, V39 (twice), V41, V42 (twice), V43, V46 (twice) and V120, respectively, resulting in the following cell lines: H4_100-41 (H4_GE-SV), H4_100-42 (H4_GE-S), H4_100-43 (H4_GE-V), H4_100-120 (H4_mC_GE-S) and H4_100-39_-46 2 (H4_GE-V1S + SV2). For the CE ${ }^{\mathrm{T} 2}$ system, cells were transduced with V102, V32, V33, V35, V36, or V37, respectively (see Supplementary Table 3), resulting in the following cell lines: H4_102-32-33 (H4_CE $\left.{ }^{\mathrm{T} 2}-\mathrm{V} 1 \mathrm{~S}+\mathrm{SV} 2\right)$, H4_102-35 (H4_CE $\left.{ }^{\mathrm{T} 2}-\mathrm{SV}\right)$, H4_102$36\left(\mathrm{H} 4 \_\mathrm{CE}^{\mathrm{T} 2}-\mathrm{S}\right)$, and $\mathrm{H} 4 \_102-37\left(\mathrm{H} 4 \_\mathrm{CE}^{\mathrm{T} 2}-\mathrm{V}\right)$.

Cells were expanded and stored in the gas phase of liquid nitrogen. For each experiment a new aliquot was unfrozen to obtain reproducible cell populations.

Induction of transgene expression. Tebufenozide (Santa Cruz, sc-280110) and (z)-4-OH-tamoxifen (Abcam, ab141943) were diluted in DMSO to a final concentration of $100 \mathrm{mM}$. To induce transgene expression, cells were incubated with $100 \mathrm{pM}$ to $100 \mu \mathrm{M}$ and a final DMSO concentration of $0.1 \%$.

Western blot. Cell pellets were resuspended in lysis buffer ( $25 \mathrm{mM}$ Tris, $50 \mathrm{mM} \mathrm{NaCl}, 0.5 \% \mathrm{Na}$-deoxycholate, $0.5 \%$ Triton X-100, $\mathrm{pH}=8.0$, protease inhibitor (Roche Applied Science, 04693124001)), incubated at $4{ }^{\circ} \mathrm{C}$ and $1,000 \mathrm{rpm}$ on a Thermomixer Comfort (Eppendorf) for $30 \mathrm{~min}$ and centrifuged $\left(16,100 \mathrm{rcf}, 10 \mathrm{~min}, 4^{\circ} \mathrm{C}\right)$. Protein concentration was adjusted to $2.08 \mathrm{mg} / \mathrm{ml}$. After blotting, the membranes were incubated overnight with primary antibodies (anti- $\alpha$ Syn $\left(15 G 7^{50}, 4 B 12\right.$ (monoclonal; Hiss, SIG-39730-200)), anti-GFP (Abcam, Ab290), anti-GAPDH (Abcam, ab9485), anti-tubulin (Sigma, T4026), anti-actin (Sigma, A2066)) diluted in $5 \%$ milk in TBS-T supplemented with $0.02 \% \mathrm{NaN}_{3}$. After washing, the membranes were incubated with a secondary antibody (rabbit-anti-rat IgG (H\&L) (alkaline phosphatase (AP)-conjugated) (Biomol GmbH, 712405-002), goat-anti-rabbit IgG (AP-conjugated) (JacksonImmoResearch, 111-055-003), goat-anti-mouse IgG (AP-conjugated) (Cell Signaling Technology, 7056)), goat-anti-rabbit (horseradish peroxidase (HRP)-conjugated) (Cell Signaling Technology, 7074), horse-anti-mouse (HRP-conjugated) (Cell Signaling Technology, 7076)) diluted in 5\% milk in TBS-T for $1 \mathrm{~h}$. After washing, the membranes were prepared for signal detection using CDP-Star (Roche Applied Science, 12041677001) for AP coupled antibodies or using the Clarity ${ }^{\mathrm{TM}}$ Western ECL Substrate (BioRad, 1705060) for HRP coupled antibodies, respectively. Chemiluminescence signals were detected with the ChemiLux camera system and the ChemoStar software (Intas).

Sucrose gradient centrifugation. Cell pellets were resuspended in $40 \mu \mathrm{l}$ SC lysis buffer ( $50 \mathrm{mM}$ Tris ( $\mathrm{pH}$ 7.4), $175 \mathrm{mM} \mathrm{NaCl}, 0.1 \% \mathrm{NP}-40,1 \mathrm{x}$ protease inhibitor) and incubated on ice for $15 \mathrm{~min}$ twice before centrifugation $\left(17,000 \mathrm{rcf}, 1 \mathrm{~min}, 4^{\circ} \mathrm{C}\right)$. Concentration of the supernatant adjusted to $50-200 \mu \mathrm{g}$ of total protein in $200 \mu \mathrm{l}$ in $50 \mathrm{mM}$ Tris ( $\mathrm{pH} 7.4), 175 \mathrm{mM} \mathrm{NaCl}$, and $0.1 \% \mathrm{NP}-40$. Centrifuge tubes were filled with buffer A (50 mM Tris- $\mathrm{HCl}$ ( $\mathrm{pH} 7.5), 0.1 \%$ NP-40, $0-60 \%$ Sucrose) in layers in the given order: $200 \mu \mathrm{l} 60 \%$ sucrose, $400 \mu \mathrm{l}$ each of $50-10 \%$ sucrose, $200 \mu \mathrm{l}$ sample without sucrose. The samples were ultracentrifuged in a Sorvall WX Ultra 90 (Thermo Scientific) $\left(40,000 \mathrm{rpm}\right.$, SW60 rotor (Beckmann Coulter), $\left.70 \mathrm{~min}, 4^{\circ} \mathrm{C}\right)$ and 12 fractions of $200 \mu \mathrm{l}$ each were collected, mixed with $800 \mu \mathrm{l}$ of $12.5 \%$ trichloroacetic acid (TCA) and incubated at $20^{\circ} \mathrm{C}$ overnight. After centrifugation at $4^{\circ} \mathrm{C}$ and $20,000 \mathrm{rcf}$ for $15 \mathrm{~min}$, pellets were washed with $1 \mathrm{ml}$ precooled acetone $\left(-20^{\circ} \mathrm{C}\right)$ and centrifuged at $4^{\circ} \mathrm{C}$ and $20,000 \mathrm{rcf}$ for $15 \mathrm{~min}$. Pellet was allowed to dry at RT for $5 \mathrm{~min}$. $30 \mu \mathrm{l}$ of $5 \mathrm{x} \mathrm{Lämmli} \mathrm{sample} \mathrm{buffer} \mathrm{were}$ added and samples were shaken at $30^{\circ} \mathrm{C}$ and $1,400 \mathrm{rpm}$ for $10 \mathrm{~min}$ followed by incubated at $96^{\circ} \mathrm{C}$ for $5 \mathrm{~min}$.

Confocal single particle spectroscopy. Cell lysis and single particle spectroscopy was performed as described previously ${ }^{51}$ using an Insight ${ }^{\mathrm{TM}}$ Reader (Evotec-Technologies). The total brightness (Itot) was adapted to 50 to $100 \mathrm{kHz}$ by dilution in RIPA buffer ( $50 \mathrm{mM}$ Tris- $\mathrm{HCl}, \mathrm{pH} 7.6,1 \% \mathrm{NP}-40,150 \mathrm{mM} \mathrm{NaCl}, 1 \mathrm{mM}$ EDTA). Laser power of the argon-ion laser $(488 \mathrm{~nm})$ was adjusted to $200 \mu \mathrm{W}$. Measurement was performed for $10-15 \mathrm{sec}-$ onds at RT, samples were scanned in a length of $100 \mu \mathrm{m}$ with a frequency of $50 \mathrm{~Hz}$ of the beam scanner and a displacement of $2,000 \mu \mathrm{m}$ of the sample carrier. Data were analysed by fluorescence intensity distribution analysis ${ }^{52}$ (FIDA) using the FCSPP evaluation software version 2.0 (Evotec-Technologies).

High content imaging (opera $\left.{ }^{\circledR}\right)$. High content screening was performed using the Opera ${ }^{\circledR}$ high-throughput confocal imaging platform (PerkinElmer Cellular Technologies GmbH, Hamburg, Germany). Nuclei were stained by with $5 \mu \mathrm{M}$ Draq5 (Thermo Fisher Scientific, 62252). All measurements were performed at RT using the 20x air objective. A detailed description of the setup and data analysis can be found in the supplementary Methods (Supplementary Fig. 11).

Fluorescence of Venus in the cytoplasm was excited using the 488 -nm laser with a laser power of $7,110 \mu \mathrm{W}$ and focus height was set to -8.0 or $-9.0 \mu \mathrm{m}$ relative to the autofocus level; all values of focus height were chosen in order to obtain optimal fluorescence yield. Fluorescence was detected using Camera 1 with an exposure time of $200 \mathrm{~ms}$ or $320 \mathrm{~ms}$ and twofold binning using a 520/35 filter. Fluorescence of mCherry was excited using the $561-\mathrm{nm}$ laser with a laser power of $3,240 \mu \mathrm{W}$ and focus height was set to $-13.0 \mu \mathrm{m}$ relative to the autofocus level; fluorescence was detected using Camera 2 with an exposure time of 7,000 ms and twofold binning using a 600/40 filter. Fluorescence of Draq5 in the nucleus was excited using the 640 -nm laser with a laser power of 3,830 $\mu \mathrm{W}$ and focus height was set to -12.0 or $-13.0 \mu \mathrm{m}$ relative to the autofocus level; fluorescence was detected using Camera 3 with an exposure time of 40 to $400 \mathrm{~ms}$ and twofold binning using a 690/50 filter. 
For data analysis, an automated image analysis tool was developed using the Acapella ${ }^{\circledR}$ software (PerkinElmer Cellular Technologies $\mathrm{GmbH}$ ) in order to quantify cellular Venus fluorescence and the fraction of condensed nuclei (Supplementary Fig. 12).

The datasets generated during the current study are available from the corresponding author on reasonable request.

\section{References}

1. Schulz-Schaeffer, W. J. The synaptic pathology of alpha-synuclein aggregation in dementia with Lewy bodies, Parkinson's disease and Parkinson's disease dementia. Acta neuropathologica 120, 131-143, https://doi.org/10.1007/s00401-010-0711-0 (2010).

2. Spillantini, M. G. et al. Alpha-synuclein in Lewy bodies. Nature 388, 839-840, https://doi.org/10.1038/42166 (1997).

3. Baba, M. et al. Aggregation of alpha-synuclein in Lewy bodies of sporadic Parkinson's disease and dementia with Lewy bodies. The American journal of pathology 152, 879-884 (1998).

4. Surmeier, D. J., Obeso, J. A. \& Halliday, G. M. Selective neuronal vulnerability in Parkinson disease. Nature reviews. Neuroscience 18, 101-113, https://doi.org/10.1038/nrn.2016.178 (2017).

5. Wagner, J. et al. Anle138b: a novel oligomer modulator for disease-modifying therapy of neurodegenerative diseases such as prion and Parkinson's disease. Acta neuropathologica 125, 795-813, https://doi.org/10.1007/s00401-013-1114-9 (2013).

6. Luna, E. \& Luk, K. C. Bent out of shape: alpha-Synuclein misfolding and the convergence of pathogenic pathways in Parkinson's disease. FEBS letters 589, 3749-3759, https://doi.org/10.1016/j.febslet.2015.10.023 (2015).

7. Bartels, T., Choi, J. G. \& Selkoe, D. J. alpha-Synuclein occurs physiologically as a helically folded tetramer that resists aggregation. Nature 477, 107-110, https://doi.org/10.1038/nature10324 (2011).

8. Fauvet, B. et al. alpha-Synuclein in central nervous system and from erythrocytes, mammalian cells, and Escherichia coli exists predominantly as disordered monomer. J Biol Chem 287, 15345-15364, https://doi.org/10.1074/jbc.M111.318949 (2012).

9. Dettmer, U., Newman, A. J., von Saucken, V. E., Bartels, T. \& Selkoe, D. KTKEGV repeat motifs are key mediators of normal $\alpha$-synuclein tetramerization: Their mutation causes excess monomers and neurotoxicity. Proceedings of the National Academy of Sciences 112, 9596-9601, https://doi.org/10.1073/pnas.1505953112 (2015).

10. Chartier-Harlin, M. C. et al. Alpha-synuclein locus duplication as a cause of familial Parkinson's disease. Lancet 364, 1167-1169, https://doi.org/10.1016/S0140-6736(04)17103-1 (2004).

11. Ibanez, P. et al. Causal relation between alpha-synuclein gene duplication and familial Parkinson's disease. Lancet 364, 1169-1171, https://doi.org/10.1016/S0140-6736(04)17104-3 (2004).

12. Singleton, A. B. et al. alpha-Synuclein locus triplication causes Parkinson's disease. Science 302, 841, https://doi.org/10.1126/ science.1090278 (2003).

13. Mittal, S. \& Bjornevik, K. beta2-Adrenoreceptor is a regulator of the alpha-synuclein gene driving risk of Parkinson's disease. 357, 891-898, https://doi.org/10.1126/science.aaf3934 (2017).

14. Cheng, P. et al. Dietary intake of iron, zinc, copper, and risk of Parkinson's disease: a meta-analysis. Neurological sciences: official journal of the Italian Neurological Society and of the Italian Society of Clinical Neurophysiology 36, 2269-2275, https://doi. org/10.1007/s10072-015-2349-0 (2015).

15. Kostka, M. et al. Single particle characterization of iron-induced pore-forming alpha-synuclein oligomers. The Journal of biological chemistry 283, 10992-11003, https://doi.org/10.1074/jbc.M709634200 (2008).

16. Tatenhorst, L. et al. Fasudil attenuates aggregation of alpha-synuclein in models of Parkinson's disease. Acta neuropathologica communications 4, 39, https://doi.org/10.1186/s40478-016-0310-y (2016).

17. Hollerhage, M. et al. Trifluoperazine rescues human dopaminergic cells from wild-type alpha-synuclein-induced toxicity. Neurobiology of aging 35, 1700-1711, https://doi.org/10.1016/j.neurobiolaging.2014.01.027 (2014).

18. Schildknecht, S. et al. Generation of genetically-modified human differentiated cells for toxicological tests and the study of neurodegenerative diseases. Altex 30, 427-444 (2013).

19. Outeiro, T. F. et al. Formation of toxic oligomeric alpha-synuclein species in living cells. PloS one 3, e1867, https://doi.org/10.1371/ journal.pone.0001867 (2008).

20. Nagai, T. et al. A variant of yellow fluorescent protein with fast and efficient maturation for cell-biological applications. Nature biotechnology 20, 87-90, https://doi.org/10.1038/nbt0102-87 (2002).

21. Hu, C. D., Chinenov, Y. \& Kerppola, T. K. Visualization of interactions among bZIP and Rel family proteins in living cells using bimolecular fluorescence complementation. Molecular cell 9, 789-798 (2002).

22. Hamilton, D. L. \& Abremski, K. Site-specific recombination by the bacteriophage P1 lox-Cre system. Cre-mediated synapsis of two lox sites. Journal of molecular biology 178, 481-486 (1984).

23. Feil, R., Wagner, J., Metzger, D. \& Chambon, P. Regulation of Cre recombinase activity by mutated estrogen receptor ligand-binding domains. Biochemical and biophysical research communications 237, 752-757, https://doi.org/10.1006/bbrc.1997.7124 (1997).

24. Esengil, H., Chang, V., Mich, J. K. \& Chen, J. K. Small-molecule regulation of zebrafish gene expression. Nature chemical biology 3 , 154-155, https://doi.org/10.1038/nchembio858 (2007).

25. Oberbek, A., Matasci, M., Hacker, D. L. \& Wurm, F. M. Generation of stable, high-producing CHO cell lines by lentiviral vectormediated gene transfer in serum-free suspension culture. Biotechnology and bioengineering 108, 600-610, https://doi.org/10.1002/ bit.22968 (2011).

26. Gan, M., Moussaud, S., Jiang, P. \& McLean, P. J. Extracellular ATP induces intracellular alpha-synuclein accumulation via P2X1 receptor-mediated lysosomal dysfunction. Neurobiology of aging 36, 1209-1220, https://doi.org/10.1016/j. neurobiolaging.2014.10.037 (2015).

27. Moussaud, S. et al. Targeting alpha-synuclein oligomers by protein-fragment complementation for drug discovery in synucleinopathies. Expert opinion on therapeutic targets 19, 589-603, https://doi.org/10.1517/14728222.2015.1009448 (2015).

28. Hoshimaru, M., Ray, J., Sah, D. W. \& Gage, F. H. Differentiation of the immortalized adult neuronal progenitor cell line HC2S2 into neurons by regulatable suppression of the v-myc oncogene. Proceedings of the National Academy of Sciences of the United States of America 93, 1518-1523 (1996).

29. Lotharius, J. et al. Progressive degeneration of human mesencephalic neuron-derived cells triggered by dopamine-dependent oxidative stress is dependent on the mixed-lineage kinase pathway. The Journal of neuroscience: the official journal of the Society for Neuroscience 25, 6329-6342, https://doi.org/10.1523/JNEUROSCI.1746-05.2005 (2005).

30. Kerppola, T. K. Bimolecular fluorescence complementation (BiFC) analysis as a probe of protein interactions in living cells. Annual review of biophysics 37, 465-487, https://doi.org/10.1146/annurev.biophys.37.032807.125842 (2008).

31. Goncalves, S. A., Matos, J. E. \& Outeiro, T. F. Zooming into protein oligomerization in neurodegeneration using BiFC. Trends in biochemical sciences 35, 643-651, https://doi.org/10.1016/j.tibs.2010.05.007 (2010).

32. Kerppola, T. K. Visualization of molecular interactions by fluorescence complementation. Nature reviews. Molecular cell biology 7 , 449-456, https://doi.org/10.1038/nrm1929 (2006).

33. Remy, I. \& Michnick, S. W. A highly sensitive protein-protein interaction assay based on Gaussia luciferase. Nature methods 3, 977-979, https://doi.org/10.1038/nmeth979 (2006).

34. Magliery, T. J. \& Regan, L. Reassembled GFP: detecting protein-protein interactions and protein expression patterns. Methods of biochemical analysis 47, 391-405 (2006). 
35. Delenclos, M. et al. Investigation of Endocytic Pathways for the Internalization of Exosome-Associated Oligomeric Alpha-Synuclein. Frontiers in neuroscience 11,172, https://doi.org/10.3389/fnins.2017.00172 (2017).

36. Price, D. L. et al. The small molecule alpha-synuclein misfolding inhibitor, NPT200-11, produces multiple benefits in an animal model of Parkinson's disease. Scientific reports 8, 16165, https://doi.org/10.1038/s41598-018-34490-9 (2018).

37. Giese, A. et al. (Google Patents, 2010).

38. Hogen, T. et al. Two different binding modes of alpha-synuclein to lipid vesicles depending on its aggregation state. Biophysical journal 102, 1646-1655, https://doi.org/10.1016/j.bpj.2012.01.059 (2012).

39. Deeg, A. A. et al. Anle138b and related compounds are aggregation specific fluorescence markers and reveal high affinity binding to alpha-synuclein aggregates. Biochimica et biophysica acta 1850, 1884-1890, https://doi.org/10.1016/j.bbagen.2015.05.021 (2015).

40. Levin, J. et al. The oligomer modulator anle138b inhibits disease progression in a Parkinson mouse model even with treatment started after disease onset. Acta neuropathologica 127, 779-780, https://doi.org/10.1007/s00401-014-1265-3 (2014).

41. Fellner, L. et al. Anle138b Partly Ameliorates Motor Deficits Despite Failure of Neuroprotection in a Model of Advanced Multiple System Atrophy. Frontiers in neuroscience 10, 99, https://doi.org/10.3389/fnins.2016.00099 (2016).

42. Sian-Hulsmann, J., Mandel, S., Youdim, M. B. \& Riederer, P. The relevance of iron in the pathogenesis of Parkinson's disease. J Neurochem 118, 939-957, https://doi.org/10.1111/j.1471-4159.2010.07132.x (2011).

43. Hillmer, A. S. et al. Converse modulation of toxic alpha-synuclein oligomers in living cells by N'-benzylidene-benzohydrazide derivates and ferric iron. Biochem Biophys Res Commun 391, 461-466, https://doi.org/10.1016/j.bbrc.2009.11.080 (2010).

44. Levin, J. et al. Generation of ferric iron links oxidative stress to alpha-synuclein oligomer formation. Journal of Parkinson's disease $\mathbf{1}$, 205-216, https://doi.org/10.3233/JPD-2011-11040 (2011).

45. Schmidt, F. et al. Single-channel electrophysiology reveals a distinct and uniform pore complex formed by alpha-synuclein oligomers in lipid membranes. PloS one 7, e42545, https://doi.org/10.1371/journal.pone.0042545 (2012).

46. Friedlich, A. L., Tanzi, R. E. \& Rogers, J. T. The 5'-untranslated region of Parkinson\&\#39;s disease $\alpha$-synuclein messengerRNA contains a predicted iron responsive element. Molecular Psychiatry 12, 222, https://doi.org/10.1038/sj.mp.4001937 (2007).

47. Hartley, J. L., Temple, G. F. \& Brasch, M. A. DNA cloning using in vitro site-specific recombination. Genome research 10, 1788-1795 (2000).

48. Micutkova, L. et al. Analysis of the cellular uptake and nuclear delivery of insulin-like growth factor binding protein-3 in human osteosarcoma cells. International journal of cancer 130, 1544-1557, https://doi.org/10.1002/ijc.26149 (2012).

49. Kuhn, P. H. et al. Regulated intramembrane proteolysis of the interleukin-1 receptor II by alpha-, beta-, and gamma-secretase. The Journal of biological chemistry 282, 11982-11995, https://doi.org/10.1074/jbc.M700356200 (2007).

50. Kahle, P. J. et al. Subcellular localization of wild-type and Parkinson's disease-associated mutant alpha -synuclein in human and transgenic mouse brain. The Journal of neuroscience: the official journal of the Society for Neuroscience 20, 6365-6373 (2000).

51. Levin, J. et al. Divergent molecular effects of desmin mutations on protein assembly in myofibrillar myopathy. Journal of neuropathology and experimental neurology 69, 415-424, https://doi.org/10.1097/NEN.0b013e3181d71305 (2010).

52. Kask, P., Palo, K., Ullmann, D. \& Gall, K. Fluorescence-intensity distribution analysis and its application in biomolecular detection technology. Proceedings of the National Academy of Sciences of the United States of America 96, 13756-13761 (1999).

\section{Acknowledgements}

This project was supported by the Lüneburg Heritage for Research in Parkinson's disease, by the Deutsches Zentrum für Luft- und Raumfahrt e. V. (DLR) (01GM1507) under the frame of E-Rare-2, the ERA-Net for Research on Rare Diseases (ARTEMIS), and the Helmholtz-Israel project and the Centers of Excellence in Neurodegeneration. We thank Janina Mielke for excellent technical support and Jochen Herms for helpful discussions.

\section{Author Contributions}

The project was mainly designed by M.B. and A.G., supported by P.K., S.L. and K.B. Creation of cell lines and experiments were performed by M.B., D.W. and P.K. Anle138c and 3-(1,3-Benzodioxol-5-yl)-5-(3-bromophenyl)$1 H$-pyrazole were synthesized by S.R., A.L. and C.G. Manuscript was written by M.B. and reviewed by D.W., P.K., S.R., A.L., C.G., S.L., K.B. and A.G.

\section{Additional Information}

Supplementary information accompanies this paper at https://doi.org/10.1038/s41598-019-45298-6.

Competing Interests: The authors declare no competing interests.

Publisher's note: Springer Nature remains neutral with regard to jurisdictional claims in published maps and institutional affiliations.

Open Access This article is licensed under a Creative Commons Attribution 4.0 International License, which permits use, sharing, adaptation, distribution and reproduction in any medium or format, as long as you give appropriate credit to the original author(s) and the source, provide a link to the Creative Commons license, and indicate if changes were made. The images or other third party material in this article are included in the article's Creative Commons license, unless indicated otherwise in a credit line to the material. If material is not included in the article's Creative Commons license and your intended use is not permitted by statutory regulation or exceeds the permitted use, you will need to obtain permission directly from the copyright holder. To view a copy of this license, visit http://creativecommons.org/licenses/by/4.0/.

(C) The Author(s) 2019 